\title{
Conhecimentos, atitudes e situação vacinal de graduandos de Medicina sobre Hepatite B
}

Knowledge, attitudes and vaccine status of medicine students about Hepatitis $B$

Conocimientos, actitudes y situación vacunal de graduandos de medicina sobre Hepatitis $B$

Renan Paes de CAMARGO ${ }^{1}$

Marina Coimbra da CRUZ $^{1}$

Marlene Cabral Coimbra da $\mathbf{C R U Z}^{2}$

${ }^{1}$ Graduando (a) do curso de Medicina da Universidade Brasil, Campus Fernandópolis - 15600-000 Fernandópolis-SP, Brasil

${ }^{2}$ Docente dos cursos de Medicina e Odontologia da Universidade Brasil, Campus Fernandópolis - 15600-000 Fernandópolis-SP, Brasil

\section{Resumo}

Introdução: A Hepatite B, devido sua ampla prevalência, representa um problema de saúde pública mundial. O vírus, encontrado em diversos fluidos corporais, apresenta alta transmissibilidade. A preocupação é ainda maior com profissionais da saúde pelo risco ocupacional, sendo os estudantes mais vulneráveis, devido sua inexperiência prática no manejo de materiais contaminados e, por vezes, falta de informações suficientes para sua proteção individual. Objetivo: avaliar o grau de conhecimento e a atitude de estudantes de Medicina quanto a Hepatite B. Material e Método: estudo de inquérito com alunos de Medicina do primeiro e quarto anos. Resultados: Como comportamentos de risco obteve-se como principal por ambas as turmas o não uso do preservativo. Respectivamente, 83,3\% e 97,7\% dos alunos do primeiro e quarto anos mostraram-se cientes do risco ocupacional da Medicina. A minoria de ambas as turmas havia esquema vacinal completo e apenas 22 alunos afirmaram terem avaliado a positividade de seu Anti-HBs. Todos os quartanistas reconheceram que biossegurança já havia sido abordada, sendo que 59,1\% a julgou boa. A maioria dos alunos de ambas as turmas respondeu corretamente quais os equipamentos de proteção individual necessários para proteção contra o vírus, mas $20,5 \%$ dos alunos do sétimo período afirmou que o ensinamento para utilização desses equipamentos deveria ser reforçado. Conclusão: faz-se necessário reforçar as orientações referentes aos meios de transmissão do HBV, maior fiscalização quanto ao status vacinal e sorologia, além de incentivar medidas de precaução tanto nos ambientes de trabalho, quanto fora deles.

Descritores: Hepatite B; Conhecimento; Riscos Ocupacionais.

\section{Abstract}

Introduction: Hepatitis B, because of its wide prevalence, represents a worldwide public health problem. The virus, found in several body fluids, has high transmissibility. Concern is even greater with occupational risk of health professionals, with students being more vulnerable due to their inexperience in handling contaminated materials and sometimes lacking of information for their individual protection. Objective: to evaluate the degree of knowledge and the attitudes of medical students regarding Hepatitis B. Material and Method: a survey study with medical students of the first and fourth years. Results: As risk behaviors, the non-use of condoms was obtained as a main factor by both groups. Respectively, $83.3 \%$ and $97.7 \%$ of the first- and fourth-year students were aware of the occupational risk of the medicine. The minority of both classes had a complete vaccination schedule and only 22 students reported having confirmed the positivity of their serology. All the fourth-year students recognized that biosafety had already been approached, and $59.1 \%$ judged it good. Most students in both classes correctly answered which individual protection equipment needed to protect against the virus, but $20.5 \%$ of the seventh-graders said that the teaching of the use of such equipment should be strengthened. Conclusion: Therefore, it is necessary to reinforce guidelines on the means of $\mathrm{HBV}$ transmission, greater surveillance regarding vaccination status and serology, as well as encouraging precautionary measures both in and out of work environments.

Descriptors: Hepatitis B; Knowledge; Occupational Risks.

\section{Resumen}

Introducción: La Hepatitis B, debido a su amplia prevalencia, representa un problema de salud pública mundial. El virus, encontrado en diversos fluidos corporales, presenta alta transmisibilidad. La preocupación es aún mayor con profesionales de la salud por el riesgo ocupacional, siendo los estudiantes más vulnerables, debido a su inexperiencia práctica en el manejo de materiales contaminados y, a veces, falta de informaciones suficientes para su protección individual. Objetivos: evaluar el grado de conocimiento y la actitud de los estudiantes de medicina en cuanto a la Hepatitis B. Material y Métodos: estudio de investigación con alumnos de medicina del primer y cuarto años. Resultados: Como comportamientos de riesgo se obtuvo como principal por ambas clases el no uso del preservativo. Respectivamente, el 83,3\% y el 97,7\% de los alumnos del primer y cuarto años se mostraron conscientes del riesgo ocupacional de la medicina. La minoría de ambas clases tenía esquema vacunal completo y sólo 22 alumnos afirmaron haber evaluado la positividad de su Anti-HBs. Todos los cuartones reconocieron que la bioseguridad ya había sido abordada, siendo que el 59,1\% la juzgó buena. La mayoría de los alumnos de ambas clases respondieron correctamente los equipos de protección individual necesarios para la protección contra el virus, pero el 20,5\% de los alumnos del séptimo período afirmaron que la enseñanza para utilizar estos equipos debería reforzarse. Conclusión: se hace necesario reforzar las orientaciones referentes a los medios de transmisión del HBV, mayor fiscalización en cuanto al status vacunal y serológico, además de incentivar medidas de precaución tanto en los ambientes de trabajo, como fuera de ellos.

Descriptores: Hepatitis B; Conocimiento; Riesgos Laborales.

\section{INTRODUÇÃO}

A Hepatite B é uma enfermidade de grande prevalência e representa um dos grandes problemas da saúde pública mundial. Estima-se que existam 350 milhões de casos em todo o mundo, além de ser a forma mais frequente de hepatite infecciosa ${ }^{1-3}$. Segundo a Word Health Organization (WHO), a prevalência de casos crônicos - definidos como positividade por período superior a seis meses para o antígeno de superfície do vírus da Hepatite B (HBV) - de cerca de 257 milhões de pessoas com óbitos em 2015 de cerca de 887 mil pessoas, principalmente devido a suas complicações ${ }^{4}$.
Pacientes com Hepatite B podem cursar com doença hepática progressiva, que pode acarretar em cirrose e carcinoma hepatocelular, cuja incidência gira em torno de $25 \%$ nos recém-nascidos portadores do vírus e de $15 \%$ nos adultos. Devido isso a importância que se deve dar à imunização dos recém-nascidos nas primeiras 24 horas de vida, Tais estágios da patologia estão ligados a maiores riscos de morbidade e mortalidade, além de implicarem consideráveis gastos em saúde ${ }^{2}$.

A vacinação é a melhor forma de prevenção contra o HBV, apresentando $95 \%$ de efetividade, e 
está disponível pelo Sistema Único de Saúde (SUS): uma dose logo ao nascer e depois associada a Pentavalente, com doses aos dois, quatro e seis meses, segundo o Calendário Nacional de Vacinação de $2017^{4,6,7}$. Além da vacinação, medidas de proteção-padrão como higienização de mãos, uso adequado de Equipamentos de Proteção Individual (EPI), manejo e descarte corretos de materiais perfurocortantes devem ser adotadas como forma de prevenção do contágio ${ }^{3}$.

$\mathrm{O}$ vírus permanece no sangue durante os últimos estágios de um período de incubação prolongado (4 a 26 semanas) e durante episódios agudos, estando presente em todos os líquidos corporais fisiológicos - veículos primários de transmissão. Pode propagar-se por contato com secreções corporais, como o sêmen, saliva, suor, lágrimas, leite materno e efusões patológicas ${ }^{1}$.

Cerca de $70 \%$ dos pacientes com Hepatite B têm o quadro subclínico, ou seja, assintomático ${ }^{1}$. No entanto, algumas pessoas podem apresentar sintomas como icterícia, colúria, fadiga extrema, além de episódios de náusea, vômito e dor abdominal. Em uma pequena parcela dos casos agudos pode haver insuficiência hepática fulminante, resultando em óbito ${ }^{4}$.

A transmissão do HBV pode ocorrer de forma vertical (de mãe para filho, ao nascimento), por meio de relação sexual, por ferimentos cutâneos, compartilhamento de seringas e agulhas entre usuários de drogas, transfusão sanguínea e em acidentes biológicos ${ }^{5,8}$.

É sabido que os hospitais e clínicas oferecem riscos de exposição a acidentes de trabalho, principalmente os riscos biológicos ${ }^{1}$. Sendo que o conceito de biossegurança diz respeito ao conjunto de medidas que objetivam a prevenção ou mesmo a eliminação destes riscos inerentes às profissões da área da saúde ${ }^{9}$. Tais acidentes, em sua maioria, resultam da manipulação de perfurocortantes, que representa um meio de transmissão de patógenos - incluindo o HBV veiculados pelo sangue. Como consequência, pode haver, além dos problemas fisiológicos, severos problemas psicológicos aos acidentados, devido à possibilidade de contaminação por vírus causadores de patologias letais ${ }^{10}$.

Com relação à formação dos profissionais da saúde, os riscos de acidentes biológicos devem ser abordados de forma prática e teórica, devendo reconhecer que os alunos, no decorrer de sua formação, a partir do momento que são inseridos nos campos de estágio, estarão sob o mesmo grau de exposição e risco que os demais membros da equipe de saúde. Portanto, é de grande importância não só conhecer, mas também colocar em prática as medidas de proteção-padrão diante de qualquer paciente, independentemente de seu diagnóstico.
Apesar destas recomendações, existem estudos demostrando certa dificuldade por parte dos profissionais de saúde em aderir às medidas de segurança e evidenciam que estes demonstram baixo conhecimento e treinamento inadequado, o que aumenta as chances de ocorrerem acidentes de trabalho ${ }^{11}$.

A infecção pelo HBV de origem ocupacional é mais frequente entre os trabalhadores de saúde com relação à população geral, o risco chega a ser 11 vezes maior entre estes profissionais ${ }^{12}$. Fatores como duração e frequência do contato e AgHBs positivo podem ser decisivos na transmissão ocupacional deste vírus ${ }^{7}$. As doenças causadas pelo trabalho e os acidentes de trabalho constituem um importante problema de saúde pública, sendo que acidentes ocorridos com agulhas causam mais de $80 \%$ das transmissões de doenças infecciosas entre os profissionais de saúde. O risco de infecção pós-exposição ocupacional com material perfurocortante pode chegar a $30 \%{ }^{12}$.

O elevado nível de infecção do HBV se deve a sua alta taxa de transmissibilidade, podendo ser transmitido mesmo em pequenas quantidades de sangue $(0,0001 \mathrm{ml})$ e saliva, além de ser capaz de sobreviver pelo menos sete dias em temperatura ambiente ${ }^{7,13}$. Além disso, vale ressaltar que este vírus apresenta infectividade 100 vezes maior que o do Vírus da Imunodeficiência Humana (HIV) ${ }^{8}$.

Diante da relevância da temática, o presente estudo teve como objetivo avaliar o grau de conhecimento, as atitudes e a situação vacinal referente ao $\mathrm{HBV}$ de graduandos do primeiro e sétimo semestres do curso de Medicina de uma universidade do interior de São Paulo (SP).

\section{MATERIAL E MÉTODO}

Trata-se de estudo descritivo, do tipo transversal, efetuado mediante a aplicação de um questionário estruturado com 14 questões, sendo 10 de múltipla escolha, incluindo dados de identificação educacional, de gênero e de idade, para levantamento sobre o conhecimento dos acadêmicos de Medicina sobre a Hepatite B, suas formas de transmissão, prevenção e imunização. Foi submetido à avaliação pelo Comitê de Ética em Pesquisa da Universidade Brasil, sob o CAAE 64556717.4.0000.5494.

A pesquisa envolveu a participação de 205 alunos da Universidade Brasil - Campus Fernandópolis, do curso de Medicina, excluindo da análise 17 graduandos do primeiro período por serem menores de 18 anos de idade, totalizando assim uma amostra de 188 alunos, sendo 44 do quarto ano e 144 do primeiro período. As entrevistas foram realizadas com os alunos no ambiente da universidade, em que estes eram abordados, explicitados sobre a pesquisa e convidados a 
participar da mesma. Os casos afirmativos assinaram Termo de Consentimento Livre Esclarecido e responderam o questionário de forma sigilosa.

Os dados foram agrupados e analisados por distribuição de frequência das respostas. O agrupamento acorreu de acordo com o período da graduação, gênero e idade.

Após a coleta de dados, os participantes abordados foram informados sobre a importância do conhecimento sobre a Hepatite B e suas formas de prevenção, transmissão, imunização e condutas diante de acidentes biológicos, conforme as questões abordadas no questionário aplicado.

\section{RESULTADOS}

Dentre as 188 pessoas que responderam ao questionário, 126 eram mulheres $(67 \%)$ e 62 eram homens (33\%), sendo que 144 estavam cursando o primeiro período do curso de Medicina e 44 estavam no sétimo período. A média etária do grupo do primeiro período corresponde a 21,1 anos e do sétimo a 23,3 anos.

No que tange a realização prévia de algum outro curso na área da saúde, $11(7,6 \%)$ alunos do primeiro semestre afirmam já terem feito, contra 5 $(11,3 \%)$ alunos do sétimo.

Com relação aos fatores de risco apresentados por cada entrevistado, obteve-se o descrito na Tabela 1. Destaca-se como principal fator de risco apresentado por ambas as turmas o não uso de preservativo durante relações sexuais: $29,8 \%$ de expostos no primeiro período e $63,6 \%$ no sétimo. Além disso, observou-se que nenhum aluno referiu já ter recebido transfusão sanguínea. Quando correlacionado os fatores de risco ao sexo dos entrevistados, encontrou-se que, de maneira geral, os homens apresentaram maior risco de contrair HBV, sendo que os itens "fez sexo sem preservativo" $(39,6 \%)$ e "já passou por alguma cirurgia na cavidade oral" $(34,9 \%)$ foram os mais assinalados pelos indivíduos do sexo masculino; já no sexo feminino, observou-se maior prevalência dos seguintes quesitos: $36 \%$ faz sexo sem usar preservativo e $37,6 \%$ não leva os próprios materiais quando vai à manicure.

Tabela 1. Fatores de risco para contrair o vírus da Hepatite B assinalados pelos estudantes de Medicina

\begin{tabular}{lccccccc}
\hline \multicolumn{1}{c}{\begin{tabular}{c} 
Atitudes/ \\
\multicolumn{1}{c}{ Fatores de Risco }
\end{tabular}} & \multicolumn{1}{c}{$\mathbf{1}^{\mathbf{0}}$ Período } & \multicolumn{2}{c}{$\mathbf{7}^{\mathbf{0}}$ Período } & \multicolumn{2}{c}{ Total } \\
\cline { 2 - 8 } & $\mathbf{N}$ & $\mathbf{\%}$ & $\mathbf{N}$ & $\mathbf{\%}$ & $\mathbf{N}$ & $\mathbf{\%}$ \\
\hline Portador de HBV na família & 8 & 5,5 & 2 & 4,5 & 10 & 5,3 \\
Passou por cirurgia geral & 23 & 15,9 & 11 & 25 & 34 & 18 \\
Passou por cirurgia oral & 33 & 22,9 & 16 & 36,3 & 49 & 26 \\
Fez tatuagem & 16 & 11,1 & 9 & 20,4 & 25 & 13,2 \\
Recebeu transfusão sanguínea & 0 & 0 & 0 & 0 & 0 & 0 \\
Fez sexo sem preservativo & 43 & 29,8 & 28 & 63,6 & 71 & 37,7 \\
Usa ou já usou drogas injetáveis & 1 & 0,6 & 0 & 0 & 1 & 0,5 \\
Não leva próprios materiais na manicure & 40 & 27,7 & 10 & 22,7 & 50 & 26,5 \\
Nenhuma das opções anteriores & 44 & 30,5 & 6 & 13,6 & 50 & 26,5 \\
\hline
\end{tabular}

Ao indagar aos estudantes se consideravam a medicina uma profissão de risco para contrair o vírus da Hepatite $B$, obtivemos resposta afirmativa de 120 alunos $(83,3 \%)$ do primeiro ano e de 43 acadêmicos $(97,7 \%)$ quartanistas. Além disso, apenas $22(15,2 \%)$ alunos do primeiro ano não souberam responder tal questionamento.

Está exposto na Tabela 2 o conhecimento relacionado aos meios de transmissão da Hepatite B e referido pelos alunos entrevistados. Destacando que $88,8 \%$ das pessoas do primeiro período afirmaram que o compartilhamento de seringas e agulhas entre usuários de drogas transmite o vírus e também $88,8 \%$ disseram que transfusões de sangue podem ser causa da transmissão. Entretanto no sétimo período $100 \%$ afirmou que compartilhar seringas e agulhas transmite a doença e 93,1\% objetou que acidentes com perfurocortantes também é um meio de transmissão.

Tabela 2. Formas de transmissão do vírus da Hepatite B reconhecidas pelos alunos de Medicina avaliados

\begin{tabular}{|c|c|c|c|c|c|c|}
\hline \multirow{2}{*}{ Formas de Transmissão } & \multicolumn{2}{|c|}{$\mathbf{1}^{\circ}$ Período } & \multicolumn{2}{|c|}{$7^{\circ}$ Período } & \multicolumn{2}{|c|}{ Total } \\
\hline & $\mathbf{N}$ & $\%$ & $\mathbf{N}$ & $\%$ & $\mathbf{N}$ & $\%$ \\
\hline Transmissão vertical & 37 & 25,6 & 23 & 52,2 & 60 & 31,9 \\
\hline Saliva Humana & 31 & 21,5 & 12 & 27,2 & 43 & 22,8 \\
\hline Relação sexual & 108 & 75 & 36 & 81,8 & 144 & 76,5 \\
\hline $\begin{array}{l}\text { Compartilhamento de seringas e } \\
\text { agulhas }\end{array}$ & 128 & 88,8 & 44 & 100 & 172 & 91,4 \\
\hline Transfusão sanguínea & 128 & 88,8 & 41 & 93,1 & 169 & 89,8 \\
\hline $\begin{array}{l}\text { Acidentes com } \\
\text { perfurocortantes }\end{array}$ & 89 & 61,8 & 41 & 93,1 & 130 & 69,1 \\
\hline Não soube responder & 10 & 6,9 & o & o & 10 & 5,3 \\
\hline
\end{tabular}

A Figura 1 demonstra a situação vacinal relatada pelos alunos, sendo que a minoria de ambas as turmas assinalou ter realizado a vacinação completa (três doses). Enquanto que, no que diz respeito a soroconversão da vacina (Anti-HBs), apenas 14 alunos do primeiro $(9,7 \%)$ e 8 do sétimo $(18,2 \%)$ relataram terem avaliado a efetividade de sua vacinação contra o HBV via Anti-HBs, sendo que $68(47,2 \%)$ primeiranistas e $5 \quad(11,3 \%)$ quartanistas não souberam responder a tal pergunta. No total, $49 \%$ dos alunos de ambos os períodos não realizaram o teste de soroconversão e $39 \%$ não souberam responder.

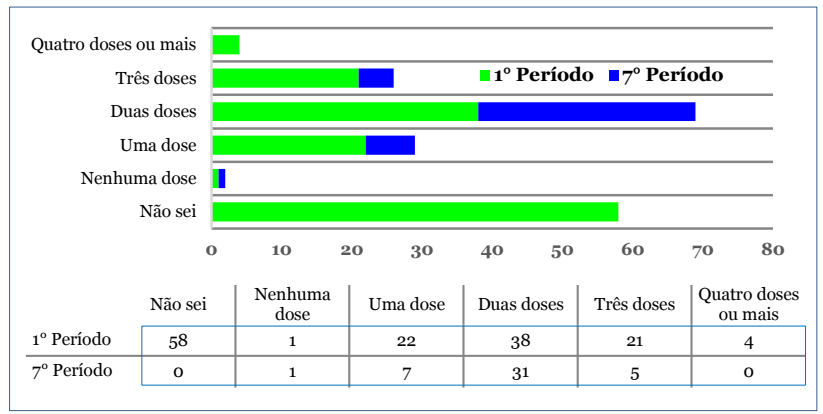

Figura 1: Estado vacinal para Hepatite B relatado pelos graduandos do primeiro e sétimo períodos do curso de Medicina.

A despeito do conteúdo de biossegurança abordado ao longo da formação acadêmica médica, encontrou-se $\mathrm{o}$ descrito na Tabela 3 quando questionados sobre a qualidade da abordagem de tal conteúdo até o momento, em cada turma. Todos do quarto ano reconheceram que o assunto já foi abordado em alguma ocasião durante o curso, sendo que a maioria $(59,1 \%)$ a considerou boa. Já dentre os primeiranistas, houve divergência nas respostas quanto ao assunto já ter sido discutido ou não, de forma que a maioria (84\%) respondeu de forma 
negativa.

Ainda nesta mesma linha de considerações, $81,8 \%$ dos alunos do sétimo e $69,4 \%$ dos do primeiro semestre souberam responder corretamente quais são os Equipamentos de Proteção Individual (EPI) necessários para prevenir infecções pelo vírus da Hepatite B ao realizar procedimentos de saúde.

Tabela 3. Qualidade da abordagem sobre biossegurança ao longo do curso segundo julgamento dos discentes

\begin{tabular}{ccccccc}
\hline \multirow{2}{*}{ Avaliação do Conteúdo } & \multicolumn{2}{c}{$\mathbf{1}^{\mathbf{0}}$ Período } & \multicolumn{2}{c}{$\mathbf{7}^{\mathbf{0}}$ Período } & \multicolumn{2}{c}{ Total } \\
\cline { 2 - 7 } & $\mathbf{N}$ & $\mathbf{\%}$ & $\mathbf{N}$ & $\mathbf{\%}$ & $\mathbf{N}$ & $\mathbf{\%}$ \\
\hline Bom & 17 & 11,8 & 26 & 59,1 & 43 & 22,9 \\
Regular & 6 & 4,2 & 14 & 31,8 & 20 & 10,6 \\
Ruim & $\mathrm{O}$ & $\mathrm{O}$ & 4 & 9,1 & 4 & 2,1 \\
Não foi abordado & 121 & 84,0 & 0 & 0 & 121 & 64,4 \\
\hline
\end{tabular}

Com relação ao treinamento recebido para utilização dos EPIs temos que: $45,1 \%$ dos acadêmicos do primeiro ciclo afirmaram ter recebido treinamento e que este foi suficiente para sua formação; 17,3\% gostariam que este conteúdo fosse reforçado ainda durante a graduação; 2,7\% declararam não ter ficado clara a habilidade ensinada e $30,7 \%$ afirmaram não terem recebido tal treinamento. Em contrapartida, 79,5\% dos alunos do sétimo período consideraram o treinamento suficiente e $20,5 \%$ acreditam que o ensinamento para utilização dos EPIs deveria ser reforçado.

Questionou-se sobre as chances de infecção do HBV na prática ocupacional em relação as chances de infecção pelo HIV, sendo que a maioria deteve conhecimento correto no sétimo período $(72,7 \%)$. No entanto, os discentes ingressantes do curso mostraram-se confusos sobre qual dos vírus representa maior risco ocupacional, de forma que a maioria $61,8 \%$ detinha conhecimento errôneo ou não souberam responder este quesito. Os dados encontram-se dispostos na Figura 2. Ainda neste item, dos alunos que já haviam feito outro curso na área da saúde, 11 deles $(68,7 \%)$ souberam responder corretamente que o HBV apresenta maiores chances de contaminação que o HIV frente a um acidente biológico.

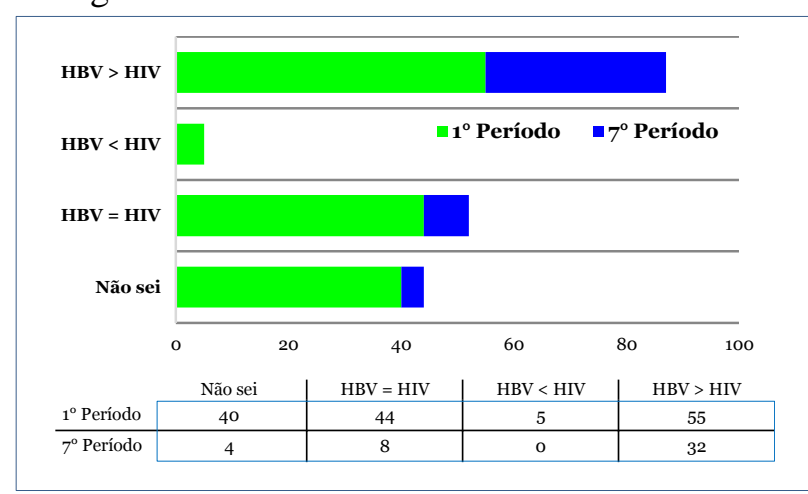

Figura 2: Risco de contrair o vírus da Hepatite B comparado ao de contrair o vírus da imunodeficiência humana segundo o iulgamento dos alunos.

Na questão referente à atitude a ser tomada pelo graduando em situação de acidente biológico, obteve-se que $63,8 \%$ dos alunos do primeiro período procederiam corretamente, no entanto, 3,5\% dos alunos afirmaram que não comunicariam o professor sobre o acidente e apenas espremeriam o local da lesão e usariam álcool gel. Dentre os alunos do sétimo período, $88,6 \%$ acertaram como agir corretamente em acidentes biológicos, sendo que nenhum indicou que deveria espremer a lesão e todos informariam seu professor sobre o ocorrido. Entre os alunos que já haviam feito curso na área da saúde, a atitude correta seria tomada pela maioria deles $(75 \%)$.

\section{DISCUSSÃO}

A maneira de maior eficácia para prevenção da infecção pelo HBV é via vacinação, cujo mecanismo de proteção decorre da produção de anticorpos (Anti-HBs) contra uma proteína de superfície do vírus ${ }^{14}$. Angelo et al. ${ }^{7}$ obtiveram em seu estudo com graduandos de Odontologia que apenas $9,9 \%$ dos avaliados realizaram o teste de soroconversão após a vacinação; enquanto que o presente estudo registrou dados análogos, com apenas $12 \%$ de alunos relatando o teste para AntiHBs. A conduta a ser tomada frente um acidente biológico depende do resultado da soroconversão do paciente, dessa forma, o desconhecimento do resultado deste teste retarda as medidas preventivas pós-exposição ${ }^{3}$.

A proteção conferida pela vacina aumenta com o número de doses e a eficácia chega a quase $100 \%$ com três doses ${ }^{15}$. Vieira et al. ${ }^{14}$ em seu estudo avaliou 58 estudantes da área da saúde, sendo que 48,2\% receberam três doses da vacina, 37,9\% receberam duas doses e $13,7 \%$ receberam apenas uma dose. Abich et al. ${ }^{16}$, ao entrevistar estudantes de Biomedicina, obtiveram que $60,2 \%$ haviam recebido três doses da vacina e $29,6 \%$ não souberam responder o número de doses que receberam. Já no presente estudo, a maioria dos alunos do primeiro período $(40,9 \%)$ afirmam não terem tomado vacina ou não souberam responder; entretanto 15,2\% tomaram uma dose, $26,3 \%$ duas doses e apenas $14,5 \%$ receberam as três doses; enquanto que no oitavo período $70,4 \%$ relataram terem recebido duas doses da vacina contra Hepatite B, 15,9\% uma dose e 11,3\% três doses, sendo que apenas um quartanista relatou não ser vacinado. Assim como Souza e Teixeira $^{17}$, encontramos que os graduandos de períodos mais avançados do curso de Medicina têm melhor conhecimento sobre sua situação vacinal quando comparado aos alunos ingressantes; no entanto nosso estudo divergiu daquele no que tange a adesão vacinal completa dos alunos, de forma que os alunos do primeiro período foram ligeiramente mais adeptos a vacinação completa da Hepatite B.

Para Oliveira et al. ${ }^{18}$, os acadêmicos da área da saúde são um grupo de risco para adquirir Hepatite $\mathrm{B}$, por isso é preocupante o número de alunos não vacinados ou com número de doses insuficientes, o que os colocam em maior risco de 
serem infectados pelo HBV, uma vez que para a soroconversão é necessário a administração de três doses da vacina.

De acordo com Shimizu e Ribeiro ${ }^{19}$, os alunos de Medicina são os que mais sofrem acidentes com perfuro-cortantes e materiais biológicos devido aos procedimentos que realizam para coletar exames de rotina. Outra razão é o fato de que estes alunos passam por campos de estágio em ambientes de saúde, desenvolvendo atividades e procedimentos invasivos para os quais muitas vezes não possuem adequado treinamento e conhecimentos sobre biossegurança, de forma que tal realidade somada à inexperiência clínica e prática torna-os mais suscetíveis a acidentes biológicos ${ }^{18}$. Em relação a atitude a ser tomada diante de um acidente biológico a maioria dos alunos de ambos os períodos procederiam de maneira correta.

A maioria dos ingressantes em cursos na área da saúde não possui o devido conhecimento sobre os riscos aos quais serão expostos, sendo as universidades responsáveis por fornecer as informações adequadas sobre este assunto no começo do curso ${ }^{20}$. Neste trabalho, entretanto a maioria dos alunos estava ciente dos riscos que encontrariam ao ingressar no curso de Medicina (83,3\% do primeiro ano e $97,7 \%$ do quarto ano), no entanto $15,2 \%$ dos acadêmicos do primeiro ano não souberam responder se o curso representa uma profissão de risco para contrair o vírus. Com relação ao ensino de biossegurança na grade curricular $84 \%$ dos alunos do primeiro ano afirmaram ainda não ter tido contato com esse conteúdo, sendo que $59,1 \%$ dos alunos do quarto ano classificam como bom o conteúdo abordado de biossegurança.

Gir et al. ${ }^{20}$ afirmam que em mais de $60 \%$ dos relatos analisados de acidente biológico não haviam informações sobre o uso de EPI. No presente estudo, a maioria dos graduandos de ambos os períodos estudados informaram corretamente quais os EPIs necessários para se proteger contra infecção pelo HBV. Com relação ao treinamento para a utilização dos EPIs, 45,1\% dos alunos do primeiro ano e $79,5 \%$ dos alunos do quarto ano consideram que a abordagem já realizada até então foi suficiente para sua formação.

Em relação as vias de transmissão do HBV, Angelo et al. ${ }^{7}$ encontraram como vias mais citadas pelos alunos: procedimentos cirúrgicos $(92,5 \%)$ e hematológica $(88,1 \%)$; além disso, os autores observaram também um elevado percentual de desconhecimento da transmissão sexual deste vírus. Semelhantemente, a via hematológica foi a mais reconhecida pelos alunos de ambos os semestres avaliados, através das designações: transfusão sanguínea $(89,8 \%$ de todos os entrevistados), compartilhamento de seringas/agulhas por usuários de drogas $(91,4 \%)$ e acidentes com perfurocortantes
$(69,1 \%)$. Em contrapartida, este estudo revelou bom conhecimento dos estudantes de Medicina em relação a possibilidade de transmissão sexual deste vírus - 76,5\% dos alunos dos dois períodos somados. Apesar de a maioria $(81,8 \%)$ dos alunos do oitavo período demonstrar conhecimento da transmissão sexual, $63,6 \%$ deles relataram comportamento de risco ao não fazer uso de preservativo.

Ainda se referindo as formas de transmissão, o trabalho de Oliveira et al. ${ }^{18}$ revelou que $91,3 \%$ dos alunos afirmaram serem os acidentes com perfurocortantes uma dessas formas e somente $6,6 \%$ afirmou não conhecer as formas de transmissão da doença. Além disso, observou que poucos tinham conhecimento correto sobre a existência da transmissão vertical, algo de grande significado, por se tratarem de acadêmicos que um dia trabalharão com mulheres e gestantes em Unidades Básicas de Saúde. Já no presente estudo, teve-se que $61,8 \%$ dos alunos do primeiro ano e $93,1 \%$ dos alunos do quarto ano responderam que acidentes com perfurocortantes é uma forma de transmissão do HBV e, similarmente, apenas 6,9\% dos alunos do primeiro ano dizem desconhecer as formas de transmissão. Quanto a via vertical, avaliou-se que apenas 25,6\% dos acadêmicos do primeiro ano tem conhecimento sobre a transmissão vertical do HBV, contra 52,2\% dos alunos do quarto. O HBV é mais infeccioso que o vírus da Hepatite C e HIV, apresentando infectividade 57 vezes maior quando comparado a este último ${ }^{21,22}$. Frente ao questionamento sobre qual vírus apresenta maior infectividade - HIV ou Hepatite B - encontrou-se, assim como outros dois estudos ${ }^{23,24}$, que a maioria dos alunos acertou que o $\mathrm{HBV}$ tem maior risco de contaminação.

Tendo em vista as atitudes/comportamentos de riscos dos discentes, um estudo ${ }^{24}$ com acadêmicos de Odontologia mostrou que uso de drogas $(95,2 \%)$ e a presença de tatuagem $(95,2 \%)$ como mais frequentes formas de exposição entre os alunos avaliados. Já no trabalho de Ferreira et al. ${ }^{22}$, também com discentes de Odontologia, verificou-se que as principais formas de exposição dos avaliados eram o não uso de preservativo $(43,3 \%)$, compartilhamento de materiais de manicure/pedicure $(38,6 \%)$ e possuir tatuagem $(27,7 \%)$. Na presente pesquisa, obteve-se que o não uso de preservativo, antecedentes de procedimentos cirúrgicos (médicos e odontológicos) e compartilhamento de instrumentos de manicure são os principais fatores de riscos para contaminação pelo HBV entre os graduandos entrevistados em ambos os períodos. Vale destacar, que os quartanistas se demonstraram mais expostos aos riscos do que os ingressantes do curso, semelhantemente ao observado no estudo de Ferreira et al. ${ }^{22}$. 


\section{CONCLUSÃO}

Conclui-se que os acadêmicos de Medicina adquiriram conhecimentos sobre Hepatite B ao longo de sua formação, além de noções de prevenção de potenciais acidentes biológicos no ambiente hospitalar; fato evidenciado pelo aumento de acertos dos acadêmicos do sétimo período em relação aos primeiranistas. No entanto, apresentaram comportamentos de risco fora do ambiente de trabalho/hospitalar, cuja cautela cabe a qualquer cidadão rotineiramente, como o uso de preservativos durante relações sexuais. Além disso, poucos alunos de ambos os períodos estavam com seu status vacinal em dia e testagem positiva do Anti-HBs, o que sugere a necessidade de uma maior orientação e, principalmente, fiscalização destes dados como prérequisito para atividades práticas de risco ocupacional.

Sendo assim, faz-se necessário reforçar as orientações referentes aos meios de transmissão do HBV e incentivar medidas de precaução tanto nos ambientes de trabalho, quanto fora deles.

\section{REFERÊNCIAS}

1. Pinheiro J, Zeitoune RCG. Hepatite B: conhecimento e medidas de biossegurança e a saúde do trabalhador de enfermagem. Esc Anna Nery. 2008;12(2):258-64.

2. Oliveira GLA, Almeida AM, Silva AL, Brandão CMR, Andrade EIG, Cherchiglia ML et al. Antivirais incorporados no Brasil para hepatite B cronica: analise de custo-efetividade. Rev Saúde Pública 2013;47(4):769-80.

3. Barbosa ASAA, Salotti SRA, Silva SMUR. Nível de conhecimento sobre Hepatite B, estado vacinal e medidas de biossegurança de profissionais de enfermagem em um hospital público do interior paulista. $\mathrm{R}$ Epidemiol Control Infec. 2017;7(2):107-12.

4. World Health Organization. Media Centre: hepatitis B [Internet]; 2017. Disponível em: http://www.who.int/mediacentre/factsheets/fs204 /en/ . Acesso em: 10 dez. 2017.

5. Divisão de Imunização. Vacina contra hepatite B. Rev. Saúde Pública. 2006; 40( 6 ): 1137-1140.

6. Ministério da Saúde (BR), Portal da Saúde: Calendário Nacional de Vacinação 2017 [Internet]. 2017. Brasília: Ministério da Saúde, $2017 . \quad$ Disponível em: http://portalsaude.saude.gov.br/index.php/oministerio/principal/leia-mais-o-ministerio/197secretaria-svs/13600-calendario-nacional-devacinacao . Acesso em: $10 \mathrm{dez} .2017$.

7. Angelo AR, Queiroga AS, Gonçalves LFF, Santos SD, Sousa CDFS, Soares MSM. Hepatite B: Conhecimento e Prática dos Alunos de Odontologia da UFPB. Pesq Bras Odontoped Clin Integr. 2007;7(3):211-16.
8. Nunes AO, Araújo TM, Santos KOB, Mascarenhas MS, Almeida MMG. Vacinação contra hepatite $\mathrm{b}$ em trabalhadores da saúde de um Município da Bahia. Rev. Saúde Col. UEFS, Feira de Santana, 2015;5(1):9-16.

9. Carvalho CMRS, Madeira MZA, Tapety FI, Alves ELM, Martins MCC, Brito JNPO. Aspectos de biossegurança relacionados ao uso do jaleco pelos profissionais de saúde: uma revisão da literatura. Texto contexto - enferm. 2009;18(2):355-60.

10.Marziale MHP. Subnotificação de acidentes com perfurocortantes na enfermagem. Rev bras enferm. 2003;56(2):164-68.

11. Oliveira AC, Gonçalves JA. Incidência de acidentes com material perfurocortante entre alunos de graduação em Ciências da Saúde. Cienc Cuid Saude 2009;8(3):385-92.

12. Simão SAF, Souza V, Borges RAA, Soares CRG, Cortez EA. Fatores associados aos acidentes biológicos entre profissionais de enfermagem. Cogitare Enferm. 2010;15(1):8791.

13.Silva-Júnior MF, Assis RIF, Gomes CLR, Miclos PV, Sousa HA, Gomes MJ. Conhecimento atual sobre a necessidade de imunização da hepatite B dos acadêmicos da área da saúde de uma universidade brasileira. Arq Odontol. 2014;50(3):131-37.

14.Vieira TB, Pereira R, Santos KF, Leal DBR. Soroconversão após a vacinação para Hepatite $\mathrm{B}$ em acadêmicos da área da saúde. Disc Scientia 2006;7(1):13-21.

15.Davis JP. Experience with hepatitis A and B vaccines. Am J Med. 2005;118(10):7-15.

16. Abich DR, Lima GCS, Lissarassa YPS, Mallet EKV, Comparsi B. Imunização contra o vírus da Hepatite B em estudantes da área da saúde. Contexto \& Saúde. 2016;16(30):77-84.

17.Souza EP, Teixeira MS. Hepatitis B Vaccination coverage and postvaccination serologic testing among medical students at a publica university in brazil. Rev Inst Med trop S Paulo. 2014;56(4):307-11.

18. Oliveira VC, Guimarães EAA, Costa PM, Lambert CC, Morais PMG, Gontijo TL. Situação vacinal da hepatite $B$ de estudantes da área da saúde. Rev Enf Ref. 2013;serIII(10):119-24.

19. Shimizu HE, Ribeiro EJG. Ocorrência de acidente de trabalho por materiais perfurocortantes e fluidos biológicos em estudantes e trabalhadores da saúde de um hospital escola de Brasília. Rev Esc Enferm USP. 2002;36(4):367-75.

20.Gir E, Caffer Netto J, Malaguti SE, Canini SRMS, Hayashida M, Machado AA. Accidents with biological material and immunization against Hepatitis B among students from the 


\section{CONFLITO DE INTERESSES}

health area. Rev Latino-Am Enfermagem. 2008;16(3):401-6.

21.Garcia LP, Blank VLG. Prevalência de exposições ocupacionais de Cirurgiões-dentistas e auxiliares de consultório dentário a material biológico. Cad Saúde Pública. 2006;22(1):97108.

22.Ferreira LQ, Oschiro AC, Cruz MCC, Camargo RP, Cruz MC. Hepatite B: conhecimento e atitudes de acadêmicos de Odontologia. Arch Health Invest, 2018;7(7):258-61.

23.Silva Júnior MF, Assis RIF, Sousa HA, Miclos PV, Gomes MJ. Conhecimento dos acadêmicos de odontologia da UFES sobre a necessidade de imunização. Rev Bras Pesq Saúde. 2013; 15(4):87-94.

24.Carneiro GGVS, Cangussu MCT. Prevalência presumível, cobertura vacinal, conhecimentos e atitudes relativos à hepatite $\mathrm{B}$ em graduandos de Odontologia da Universidade Federal da Bahia. Rev Odontol UNESP. 2009;38(1):7-13.
Os autores declaram não haver conflitos de interesse.

\section{AUTOR PARA CORRESPONDENCIA}

\section{Marlene Cabral Coimbra da Cruz}

mcoimbracruz@gmail.com

Submetido em 22/10/2018

Aceito em 12/03/2019 